\title{
STUDIUM: YOUR PERSONAL MOBILE STUDY ON-THE-GO
}

by

Fariha Ahmed

HBA, International Relations, Political Science and French, University of Toronto, 2018

\author{
A Major Research Project \\ presented to Ryerson University \\ in partial fulfillment of the \\ requirements for the degree of \\ Master of Digital Media \\ in the Program of \\ Digital Media
}

Toronto, Ontario, Canada, 2019

CFariha Ahmed, 2019 


\section{Author's Declaration for Electronic Submission of an MRP}

I hereby declare that I am the sole author of this MRP. This is a true copy of the MRP, including any required final revisions.

I authorize Ryerson University to lend this MRP to other institutions or individuals for the purpose of scholarly research.

I further authorize Ryerson University to reproduce this MRP by photocopying or by other means, in total or in part, at the request of other institutions or individuals for the purpose of scholarly research.

I understand that my MRP may be made electronically available to the public. 


\title{
STUDIUM: YOUR PERSONAL MOBILE STUDY ON-THE-GO
}

\author{
Fariha Ahmed \\ Master of Digital Media \\ Digital Media \\ Ryerson University, 2019
}

\begin{abstract}
The landscape of studying is changing. There are now increasingly more mobile devices that allow people to learn content in numerous ways. This means that mobile devices play a large role in how a whole new generation of children, adolescents, teenagers and young adults understand information. Studium is a mobile application prototype that I have created to demonstrate how mobile devices can be used as a learning tool to enhance academic performance among postsecondary students. The objective of Studium is to illustrate how artificial intelligence can be incorporated into mobile learning applications to improve one's studying by generating instant practice tests based off notes from lectures or readings. Studium will also demonstrate how traditional learning theories and strategies such as the spacing effect and the lag effect can be implemented into learning applications using brief mindfulness breaks, which incorporates an element of mindfulness that mobile learning applications often lack.
\end{abstract}




\section{Acknowledgements}

For helping me navigate this new journey in my academic career, I would like to personally thank the staff and faculty of the Master of Digital Media; the Master of Digital Media cohort of 2018-2019 and Dr. Naimul Khan, my supervisor. A special thank you is owed to my family and friends for their never-ending support, which is what kept sustaining my perseverance to keep going even when I faced moments of self-doubt. Last but not least, thank you to my parents for their constant love and sacrifices that allowed me to have the privilege of self-discovery and

opportunities that they themselves did not receive in life. It would not have been possible without any of these truly wonderful people in my life. 


\section{Table of Contents}

Author's Declaration for Electronic Submission of an MRP ….............................................. ii

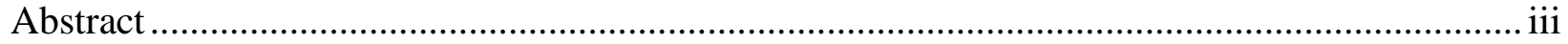

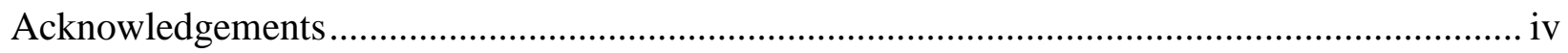

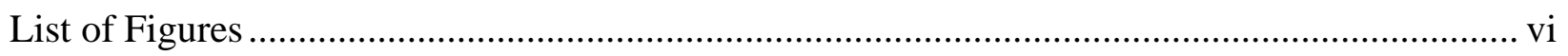

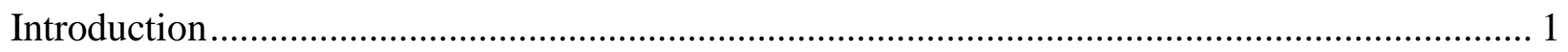

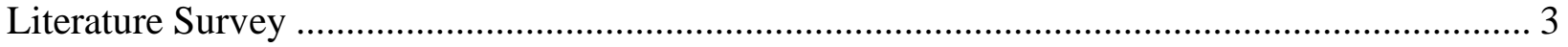

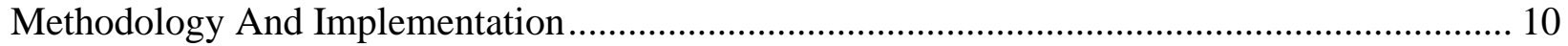

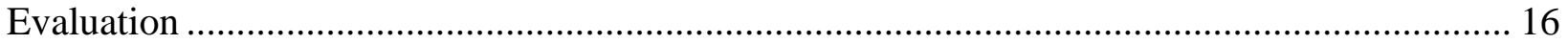

Conclusions, Summary and Future Work ............................................................................ 19

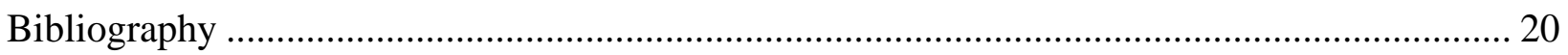




\section{List of Figures}

Figure 1.1 A Diagram of the Leitner System.................................................................. 7

Figure 2.1 The Stanford Design Thinking Process ............................................................ 12

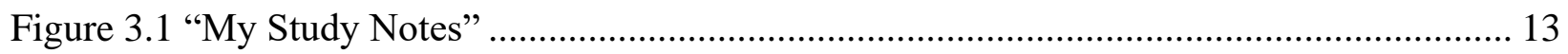

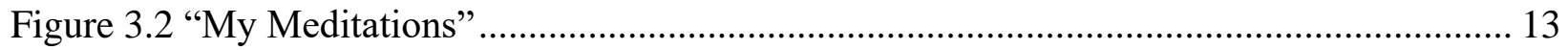

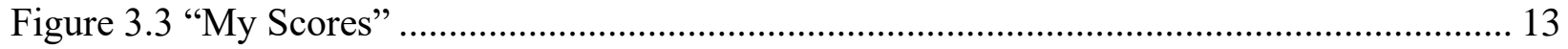

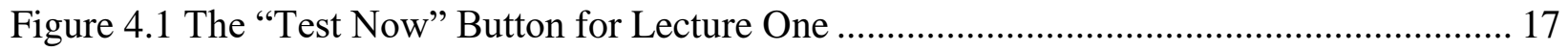

Figure 4.2 The Mindfulness Break Students Found Abrupt ................................................. 17 


\section{Introduction}

According to the Global System for Mobile Communications (GSMA), over 5 billion people in 2017 were connected to mobile services (GSMA Intelligence, 2018). Billions of people are able to consume digital content in different ways, and this means the way that students study has changed because of their access to information through mobile devices. Studium is a mobile application (app) concept that I have created, which would allow students to upload their notes, while artificial intelligence (AI) would generate practice tests in either fill-in-blank or multiplechoice format based on these notes. Mindfulness breaks would also take place in between practice tests when the AI would sense that the student requires a break from studying or when the student would schedule these breaks themselves. In this project, I created an unreleased prototype of Studium to demonstrate how it would ideally function on a mobile device.

I will argue that mobile devices including smartphones and tablets should be viewed as essential learning tools because these devices foster positive learning outcomes through mobile applications that are able to enhance understanding among students. Students also demonstrate an openness towards incorporating these devices into their learning in the first place. Firstly, I will illustrate this by conducting a review of quantitative studies, which will demonstrate that mobile devices can generate better learning results than traditional methods. This is evident among studies on English learners and students with different forms of disabilities. Secondly, I will illustrate that mobile devices can be effective at increasing knowledge retention among students because they can incorporate traditional learning theories and strategies including the spacing effect, spaced repetition, and the lag effect. This will be demonstrated in how the Studium prototype was built to incorporate these theories and strategies into how it allows 
students to study. Lastly, I will discuss the results from user acceptance testing involving ten students from different programs of study who tested out the Studium prototype. This will demonstrate that mobile devices should be incorporated into learning environments in postsecondary education because students effortlessly demonstrate a willingness and ability to adapt their learning and studying methods towards using mobile learning apps. Studium will also illustrate how artificial intelligence can be incorporated into mobile learning apps to augment a student's academic performance and that mobile learning apps can address mental health by incorporating meditation and mindfulness breaks. Studium will ultimately contribute towards the scholarly discourse on the effectiveness of mobile devices as learning tools that can increase efficient studying while strengthening memory and knowledge retention. 


\section{Literature Survey}

What firstly demonstrates the need for mobile devices to act as learning tools at the postsecondary level is the openness and positive attitude that is demonstrated by post-secondary students towards incorporating these devices into their learning in the first place. For instance, Pennington et al (2010) conducted a study where undergraduate students responded positively towards using their cellphones as a tool to study organic chemistry. The undergraduate students in the study were given organic chemistry flashcards that were viewable on their cellphones through Mobile PowerPoint with the aim of allowing them to study in the midst of completing everyday tasks such as waiting in line at the movies, hanging out with friends or being a passenger in car (Pennington et al, 2009, p. 2). The results of the study found that students had generally positive attitudes towards accessing study material on their cellphones and perceived their phones as a useful studying tool given that their phones were constantly in their possession and that they could study with these devices at any location or time. Another study with positive feedback on learning with mobile devices was conducted by Thornton and Houser (2005) on 333 Japanese university students. All the students in the study owned a mobile phone and during the study, 100-word English vocabulary lessons were emailed to 44 of these students (Thornton and Houser, 2005, p. 217). The results illustrated that $71 \%$ of the students actually preferred accessing their English lessons on their mobile phones rather than on their computers, while 93\% of students in the study felt that mobile phones are an important learning tool. These studies demonstrate that the first approach that must be taken towards implementing the use of mobile devices as a learning tool at the post-secondary level is first being aware that a willingness exists among post-secondary students to use their devices to enhance their learning and understanding. The openness that post-secondary students demonstrate towards using these devices in their 
curriculum means that mobile learning apps have the potential to be strong learning tools since students are less intimidated to utilize these devices in the first place.

The second area of research illustrating the potential for using mobile devices as learning tools is how learning with mobile devices brings about positive learning outcomes among English learners. This area of research is relevant towards the subject of learning with mobile devices because English learners are students who are required to demonstrate their comprehension in multiple different ways including verbally, auditorily, or by simply comprehending the nuances of the English language. Mobile devices are shown to generate positive learning outcomes among English learners especially in a study conducted by Basoglu and Akdemir (2010) on 66 undergraduate students who attended a public university in Turkey. The results of the study showed that vocabulary among students improved more when using their mobile phones to study rather than using flashcards on paper (Basoglu and Akdemir, 2010, p. 5). Similarly, the results of a study conducted by Thornton and Houser (2005) found that students who were told to access English lessons on mobile email apps demonstrated more comprehension than students told to study the same learning material on paper. Individuals with different forms of disabilities and special needs are also shown to demonstrate positive learning outcomes from using mobile devices to learn as demonstrated by Fernández-López et al (2012) who conducted a study on 39 students in Spain with special education needs. The students in the study were assessed on using a learning platform for iPad and iPod touch devices called "Picca," which encompassed central phases of learning like preparation, evaluation, and use. The results showed that certain skills were increased among students including environmental awareness by $7.59 \%$, language skills by $5.67 \%$, math skills by $5.56 \%$, social skills by $4.23 \%$, and autonomy 
skills by $7.26 \%$ (Fernández-López et al, 2012, p. 85). The study illustrated that these basic skills were enhanced among students because they were able to access user interfaces accommodated towards their unique needs and activities that they were not previously able to access. This area of research illustrates that mobile devices are worth being adopted as learning tools given how knowledge and comprehension is shown to increase using these devices rather than traditional methods like paper flashcards. Not only are students shown to feel open towards incorporating these devices into their learning, but these devices are capable of also enhancing their learning outcomes. Moreover, students are shown to increase their knowledge and skills because mobile learning apps can be tailored to their unique needs and how they respectively learn, which illustrates that they are efficient learning tools.

The foundation of Studium is based on implementing different learning theories and strategies proven to be effective for enhancing academic performance among students. Repetitive testing is one of the first methods that Studium implements, which is shown to be an efficient method of retaining information and producing higher results on examinations. Repetitive testing refers to the process of studying by repeatedly completing practice tests rather than just solely studying repeatedly. Butler (2010) conducted a study at the Washington University on 48 undergraduate students and 4 experiments to observe how both the process of repeated testing and repeated studying affect the ability of students to transfer and retain knowledge (Butler, 2010, p. 1119). The students involved in the study were required to take practice tests based on reading passages or either re-study them. The results illustrated that repeated testing proved to be better at enhancing the transfer of knowledge because it allows for students to gain a further understanding of learning material while retaining information (Butler, 2010, p. 1131). The study 
thereby found that the likeliness of a student successfully recalling information from their memory is highly increased when completing practice tests (Butler, 2010, p. 1124). Similar results were produced in a study conducted by Johnson and Mayer (2009) where the subjects involved in the study were told to watch a narrated animation of a lightning formation, while subsequently receiving tests with new inferential questions. The study found that restudying the entire slideshow was less effective than completing practice tests, which were shown to enhance knowledge transfer (Johnson and Mayer, 2009, p. 621). The positive learning outcomes generated from repeated testing demonstrate that Studium's approach towards allowing students to study their notes through completing practice tests is a valid studying method. This is due to how repeated testing is proven to increase knowledge transfer and enhance understanding more than simply restudying learning material.

A central component of Studium's structure of generating practice tests is implementing spaced repetition and the spacing effect. The spacing effect refers towards a memory advantage that takes place when sessions consisting of studying different learning material are spread or spaced out from one another (Kapler, Weston and Wisehart, 2015, p. 38). Spaced repetition is a way of implementing the spacing effect through testing individuals on more difficult and newly introduced concepts, while they are tested less frequently on less difficult or older information, which is also implemented by the language learning app, Duolingo (Settles and Meeder, 2016, p.1850). An example of spaced repetition is the Leitner system, which is a method of using flashcards proposed by German science journalist Sebastian Leitner in the 1970s. In this method, individuals are tested less frequently on correctly answered cards and more frequently on incorrectly answered cards (Settles and Meeder, 2016, p.1850). Duolingo uses spaced repetition 
to enhance language learning by testing users more frequently on vocabulary and grammar that they tend to answer incorrectly (Settles and Meeder, 2016, p.1850). Another important learning strategy that Studium strives to implement is the lag effect. Similar to the spacing effect, the lag involves individuals recalling more information when there are longer lags between studying sessions rather than shorter lags (Melton, 1970). Studium aims to implement spaced repetition and the spacing effect by spacing out practice tests with mindfulness breaks and testing students on areas of their notes that they encounter most difficulty with learning and memorizing. Studium will also implement the lag effect depending on whether the user chooses to increase the length of their mindfulness breaks in between tests. These mindfulness breaks will also prove to be beneficial as meditation training incorporated into post-secondary education is shown to garner positive results. For instance, a study conducted by Ramsburg and Youmans (2013), found that knowledge retention among students in three psychology courses were enhanced by meditation training because students reported feeling a decreased sense of anxiety and an increased sense of calmness. This demonstrates that combining mindfulness with studying can generate positive learning outcomes.

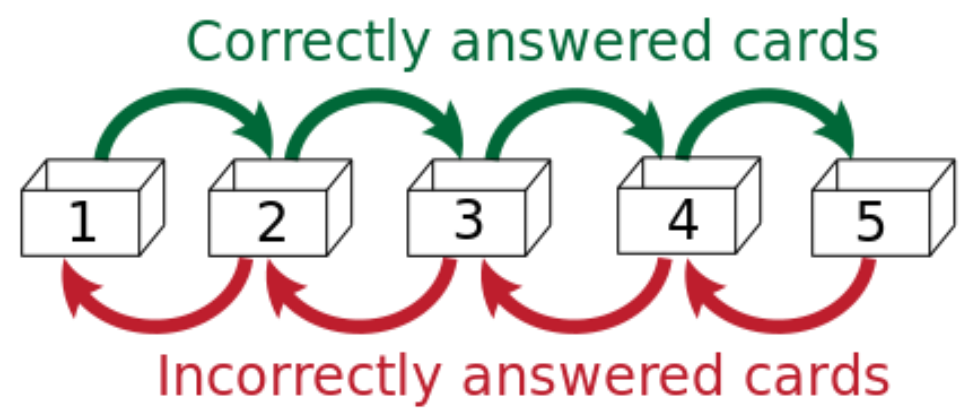

Figure 1.1 A diagram of the Leitner System. From Leitner system, by Zirguezi, 2012, https://commons.wikimedia.org/wiki/File:Leitner_system_alternative.svg. 
According to Kang (2016), the "spacing effect" is proven to generate positive learning outcomes among students than repetitively studying many concepts simultaneously within a short period of time. This is illustrated in a study conducted by Kapler, Weston and Wisehart (2015) on 169 undergraduate students who were told to review material from a national science presentation either eight days or one day after the lecture using an online review before having to complete a final test on all the material five weeks after (Kapler, Weston and Wisehart, 2015, p. 38). Students ended up performing better on this test than when they reviewed the studying material eight days after the lecture had taken place (Kapler, Weston and Wisehart, 2015, p. 38). In a similar study conducted on 126 seventh grade students by Rohrer, Dedrick and Stershic (2014), performance for studying mathematics was better when students completed interleaved practice rather than studying all the material in one chunk. This demonstrates that Studium's implementation of the "spacing effect" is essential for allowing students to study more efficiently and retain knowledge as it is proven to enhance academic performance. This is why the artificial intelligence in Studium would ideally suggest a studying schedule to the student for when each practice test should be completed, which allows the benefits of the spacing effect to take place.

Different forms of artificial intelligence can be used to aid students with their learning. For instance, Intelligent Tutoring Systems (ITSs) simulate the behaviour of human tutors through providing information in an interactive manner rather than using books (Emran and Shalaan, 2014, p. 393). This is also done through utilizing techniques like error detection and interactive problem solving (D’Mello and Graesser, 2014, p. 234). An example is Writing Pal, an ITS which provides writing strategy training to students by assessing the quality of their essays and providing feedback (McNamara, Crossley and Roscoe, 2013, p. 499). Similarly, MetaTtutor 
affects the note-taking activities of students by interacting with their prior knowledge (Trevors, Duffy and Azevedo, 2014, p. 507). All of these systems use Natural Language Processing (NLP), which is what allows computers to comprehend, analyze and draw meaning from human language in useful ways (Emran and Shalaan, 2014, p. 393). Intelligent Languages Tutoring Systems (ILTSs) also use NLP techniques that allow the user to input words or sentences, while subsequently receiving immediate feedback (Emran and Shalaan, 2014, p. 393). Studium would use NLP to create fill-in-blank fields by identifying the relevant content to test students on, while evaluating the input of their responses as either correct or incorrect. 


\section{Methodology and Implementation}

Building Studium was based on following the five main stages of the Stanford Design Thinking Process, which was created by the Hasso Plattner Institute of Design at Stanford University, one of the world's leading design schools. The Design Thinking Process encompasses these stages in the following order, which are also not necessarily always linear: empathize, define, ideate, prototype and test. Another phase called "assess," would ideally follow "test," but since Studium was a very short-term project, it was not reached. The "empathize" stage involved finding any ongoing problems that I could observe in post-secondary education. Throughout my research, I found that the recurring "grade drop" was still an ongoing issue as students continue to encounter lower grades when transitioning from high school into their first year of post-secondary education. For instance, a survey conducted by Maclean's magazine found that only $7 \%$ of students at Ryerson, $21 \%$ at McMaster University and $10 \%$ of students at York University managed to maintain their grades in order to keep their funding into their second year. This brought me to the second stage of the design thinking process, "define," which involved conducting further research into this "grade drop" and identifying potential reasons why. As one may infer, there is no single explicit reason why this phenomenon occurs for so many different students as circumstances are different for every student. However, one thing I could observe in the "define" stage is that postsecondary students often have numerous commitments from maintaining their grades to being involved in extracurricular activities, while also working either part-time or even full-time in some cases. Subsequently, I created a user persona called "Busy Brenda," based on undergraduate students who are required to memorize and learn large amounts of information for examinations but who encounter a lack of time to study because of having multiple extracurricular and work 
commitments. This persona also includes first year undergraduate students (along with undergraduate students in other years) finding it difficult to transition into post-secondary education and who encounter lower grades in their post-secondary classes. Thus, the next stage, "ideate," involved brainstorming a solution that could aid students represented by the "Busy Brenda" persona. That was when the idea of "Studium" was born. In other words, I thought of Studium as a solution to allow students to study on-the-go with their mobile devices and save time by having artificial intelligence generate practice tests based on their lecture notes or readings. This solution would ideally cater to the "Busy Brenda" students by allowing them to quickly review their notes before a lecture or exam without taking up additional time by having them make their own studying material like flashcards, which other popular studying apps often require. Studium would be ideal for letting students easily study on-the-go at any time whether that be during their commutes or at a break from their part-time job. I also incorporated the idea of optional mindfulness breaks taking place in between tests to place a focus on improving the mental health of "Busy Brenda" students who encounter high levels of stress in their undergraduate education. This led me to the fourth stage, "prototype," which entailed creating a prototype on Adobe XD of how Studium would ideally function with different features from storing notes to generating practice tests. This prototype was not coded and only contained clickable user interface (UI) elements like buttons, which would lead to different pages. Finally, the last stage, "test," involved having ten different undergraduate students at Ryerson test out the app. The results of this testing will be further discussed in the next section. 


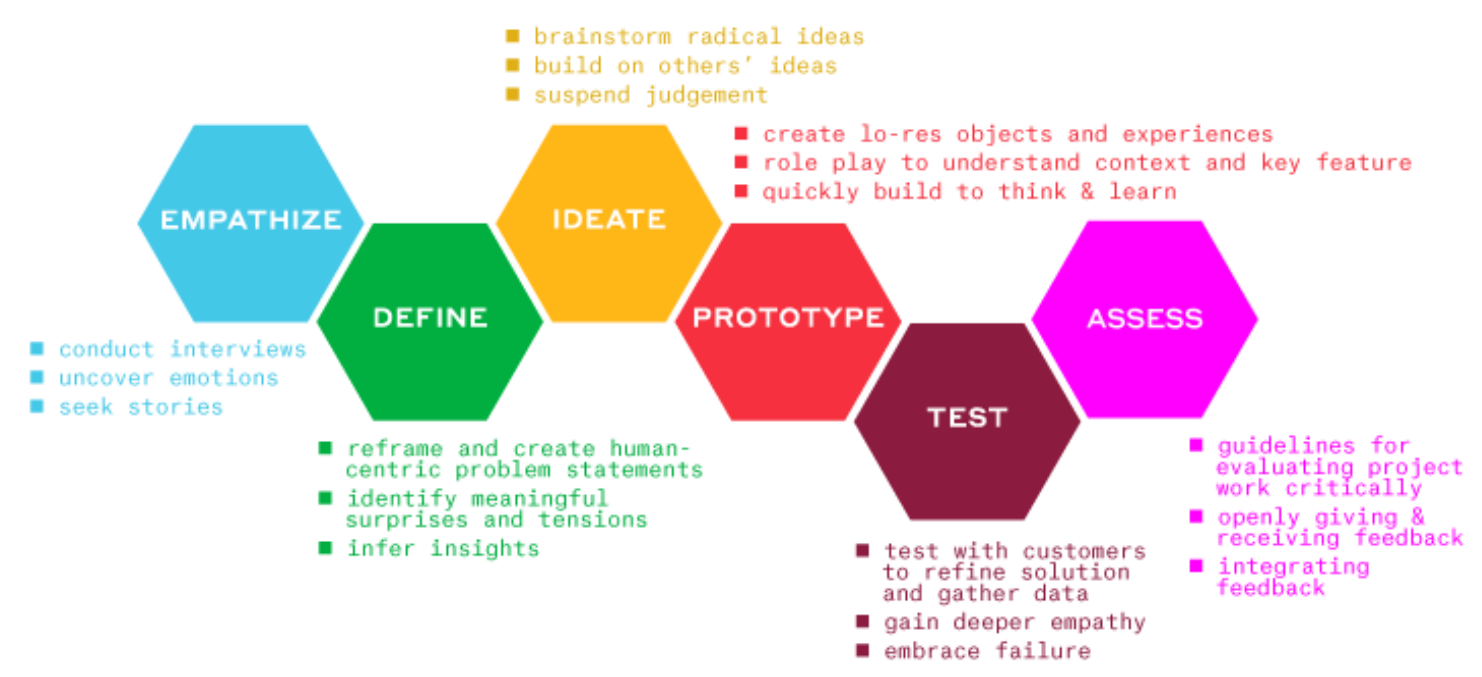

Figure 2.1 The Stanford Design Thinking Process. From Design Thinking Process Diagram, by Hasso Plattner Institute of Design at Stanford University, 2019, http://dschool.stanford.edu./executiveeducation/dbootcamp. Copyright 2019 by Hasso Plattner Institute of Design at Stanford University.

Following the stages of the Stanford Design Thinking Process also involved revisiting the "prototype" phase where I coded the final prototype of Studium. I used Android Studio to build this prototype, which is used for Android app development and is the official Integrated Development Environment (IDE) for Google's Android System. What made the final prototype different than the one created with Adobe XD is that it was actually functionable by allowing the user to type and actually complete practice tests while experiencing mindfulness breaks in between tests. This prototype thereby visually demonstrates the principles of spaced repetition, the spacing effect and the lag effect combined with the benefits of mindfulness. It must be noted that this prototype did not contain artificial intelligence but was coded to illustrate how the app would ideally function. The prototype had three main sections: "My Study Notes," "My Meditations" and "My Scores." The "My Study Notes" page allows users to view notes from different lectures, keep track of studying for upcoming exams and generate practice tests based off their notes. "My Meditations" allows users to access a selection of different meditations and meditate without having to complete practice tests, which already have brief mindfulness breaks 
incorporated into them. "My Scores" is where users can view their scores from practice tests and view statistics such as whether they are performing better in fill-in-blanks or multiple-choice formats and their average score. Lastly, another page would ideally exist in the future called "My Note-Taker," which would guide students in taking better notes in their classes.

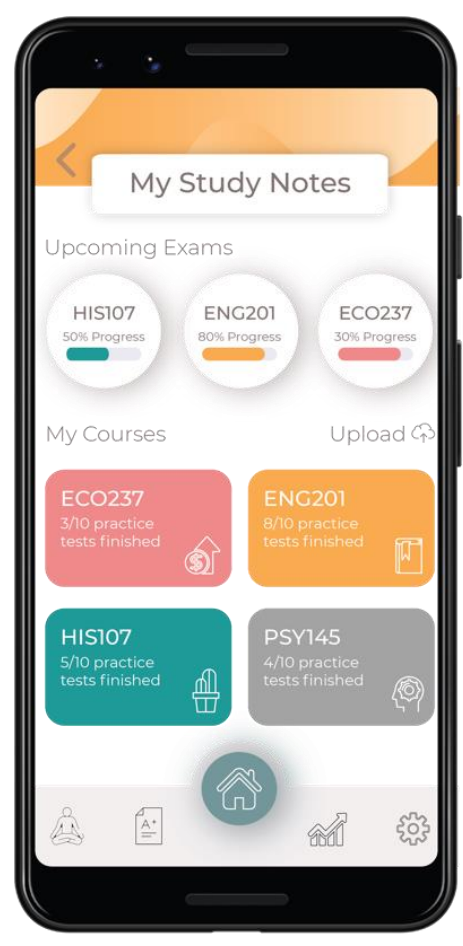

Figure 3.1 "My Study Notes"

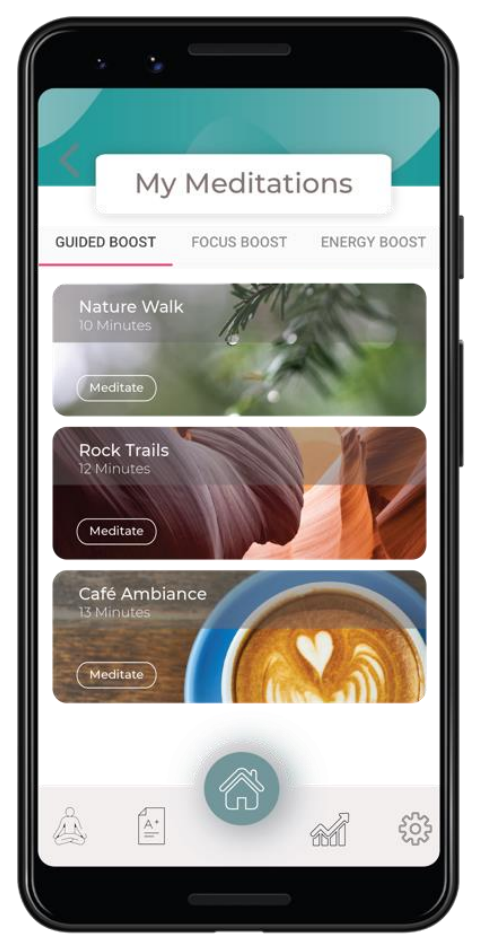

Figure 3.2 "My Meditations"

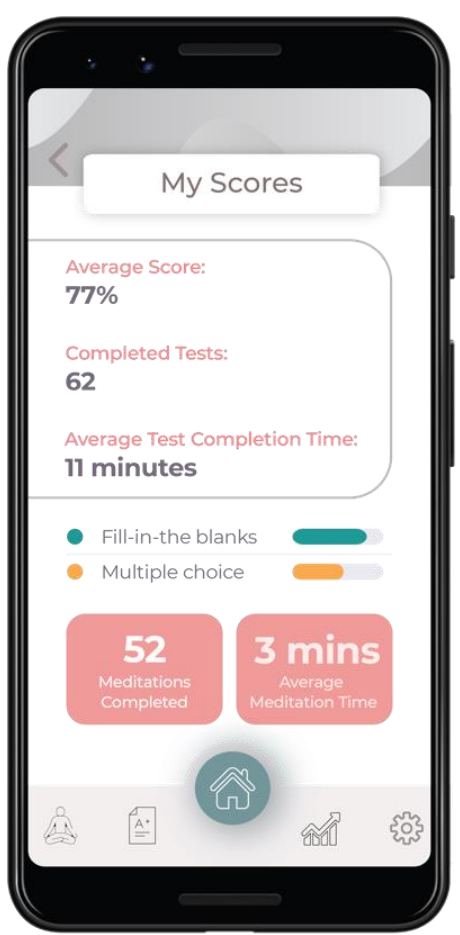

Figure 3.3 "My Scores"

The front-end of the final prototype comprising of the components forming the user-interface was coded with XML (Extensible Markup Language), which is a lightweight markup language that is used for designing layouts in Android Studio. There are also different types of layouts in Android Studio that can be used for arranging UI content such as linear layout, which is used to place elements in a top-to-bottom fashion or relative layout, where elements are positioned in relation to other elements. The layout I used for this prototype is called a "constraint layout," which is similar to a relative layout but is more flexible by allowing for dragging and dropping 
elements without specifying their exact positions in XML. This works by placing constraints on each element to either other objects, guidelines or within their container, which holds other elements together. The UI elements for every screen such as backgrounds and buttons were redesigned on Adobe Illustrator and imported as PNGs (Portable Network Graphics) into Android Studio as drawable resources, which represent graphical UI elements. Another key front-end component was the usage of fragments for the "My Meditations page." Fragments in Android Studio are parts of a UI that can be reused and are self-contained by having one activity (a screen) act as a host holding them together. In other words, fragments are a sub-activity (subpages) within one host activity. Fragments were used in the "My Meditations" page to form the content within three tabs at the top of the screen separating different meditation types such guided meditations, meditations for improving focus and increasing energy. Therefore, each section of meditations was a different fragment within the "My Meditations" page. Users could then horizontally scroll through these sub-pages, while accessing them by clicking the top tabs.

The back-end of the prototype, also known as the server side of the application that is responsible for allowing the app to function, was coded with java. The most reoccurring component in the back-end was the OnClickListeners for different buttons. This allowed for buttons to lead the user to different screens once clicked. Secondly, the form validation method was used to demonstrate how the fill-in-blank tests would work. This method is traditionally used for verifying usernames and passwords by creating a form and adding different text input fields for the user to input text and have their responses subsequently validated as either incorrect or correct. I made a mock lecture note document and created different fill-in-blanks sections by adding text input fields where the user could input text and have it validated based on answers 
that I had pre-determined from the mock lecture notes. This was achieved by using conditional statements, which would allow for certain parts of the code to be executed depending on whether certain conditions were true or false. For instance, if the user were to input the wrong answer or leave the entire field empty and subsequently click the "check" button, the first conditional statement would allow there to be an error message in red displayed beneath the text input field that would indicate incorrectness. This error message would also contain the correct answer. If the user were to input the correct answer and click the "check button," the error message would become green and say “correct." Lastly, a 10-second mindfulness break with a light meditation sound was added with a countdown timer. This mindfulness break was coded so that it would appear after the right arrow button to visit the next page on the second test was clicked. This mindfulness break would demonstrate how artificial intelligence would ideally sense that the user needs a brief break from studying, while the top of the screen would subsequently say "looks like you need a break." This break would add the element of the lag effect and spacing effect by having intervals of practice tests spaced out with mindfulness breaks taking place in between. This would further place a focus on enhancing mental health by helping reduce stress especially with different types meditation sounds incorporated into the mindfulness breaks. 


\section{Evaluation}

A total of 10 undergraduate students from Ryerson University tested out the final prototype of Studium. During this user acceptance testing, 8 of 10 students mentioned that they would use Studium as a tool in their studying. Moreover, 2 students stated that they would not use the app because it would not be effective for their studying since their exams are based more on case studies and applying logic in different scenarios rather than being tested on solely facts. Students who stated that they would use Studium to study also mentioned that they would use the app to study only in certain contexts. For example, 1 student mentioned they would use Studium to study during a commute because they would find it easier to study with the app than carrying a huge stack of paper. Another mentioned that they would only use it for a quick review rather than a three-hour study session to avoid simply memorizing their notes. Additionally, 2 students also said they would use the app because they do not enjoy making practice tests themselves and believe Studium would make things more efficient by generating practice tests for them. Seven students mentioned they would find it useful to briefly meditate or have a moment of mindfulness in between their studying. In particular, 1 student mentioned that they would find this useful because they tend to "overstudy" themselves, while another stated that they like how Studium would ideally determine when they should take a break rather than having to schedule it themselves. According to 9 students, the mindfulness break took them off-guard when completing the practice test and they mentioned that the usage of a warning or some form of a visual cue informing them that the break was coming up would make it feel less abrupt. Students also differed in opinion on whether Studium should allow students to skip this break as 1 student stated they would prefer to skip the break as they would not like to break their concentration 
while studying. However, another student stated that they would prefer having a mandatory break from always looking at their phone screen. In regards to the test format, 5 students stated that they find the fill-in-blanks test format more effective for studying. However, 5 students, including those who did not find fill-in-blanks effective, mentioned that they would prefer multiple choice over fill-in-blanks as a general test format. Only 2 students found some aspect of the app to be unnecessary. The first is the note-taker feature, which the student mentioned was redundant since every student has their own style of note-taking that they already use frequently. Another student mentioned that the meditations and mindfulness breaks were not necessary at all as they would prefer to take breaks on their own time in their own way. All students said they found Studium to be straightforward to use, however there were certain elements that were a bit confusing. For instance, 5 students stated that the "test now" button on the first lecture note page was hard to find since it appeared to blend into the top navigation bar.

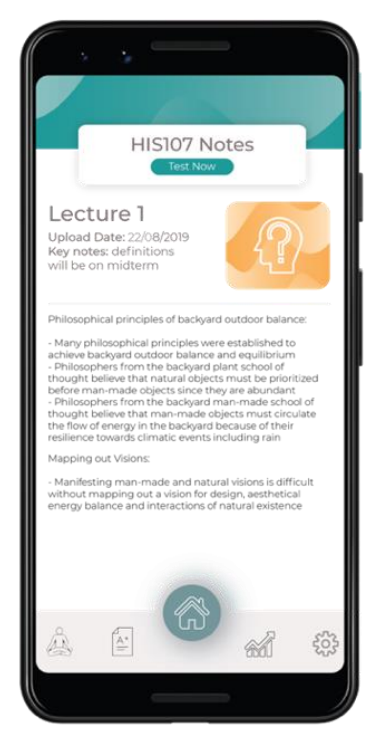

Figure 4.1

The "Test Now" Button for Lecture One

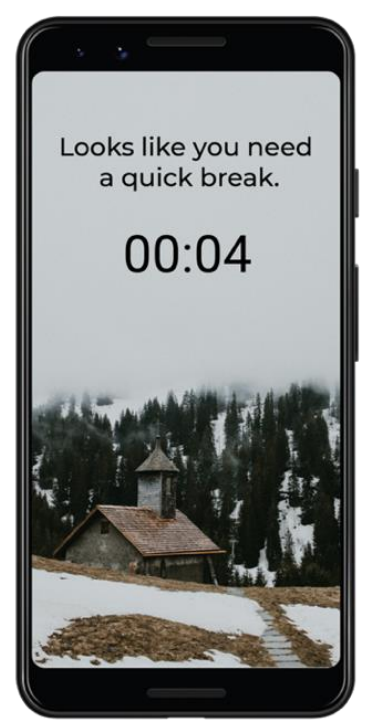

Figure 4.2

The Mindfulness Break Students Found Abrupt 
The results of the user acceptance testing demonstrate that the need for using mobile devices as a learning tool does exist because students are ready to incorporate their mobile devices into their studying as demonstrated by the majority of the students involved in Studium's user testing who said they would use the app to study. Moreover, the need for mindfulness resources is also evident at the post-secondary level as the majority of students also stated that they would find Studium's mindfulness breaks as a useful component in their studying. This is significant because if post-secondary students feel as though meditation and mindfulness is needed, then that might even indicate potential signs of a lack of these resources in their educational environments. Although students found the mindfulness break to have caught them off-guard, they mentioned that having a warning that the break was coming up would make it less abrupt. Studium thereby illustrates that the spacing effect can be incorporated into mobile apps by using mindfulness breaks because the students involved in user testing have shown that they are open towards having these breaks incorporated their studying. The overall significance of Studium's user testing is that it illustrates that students are capable and willing to adapt to using mobile devices as learning tools in their studying as long as these devices are catered towards their individual learning in their respective fields of study. 


\section{Conclusions, Summary and Future Work}

Mobile devices are capable of being effective learning tools as illustrated by the quantitative studies on English Learners and students with disabilities who demonstrate better learning outcomes from implementing these devices into their learning. User acceptance testing results from Studium demonstrate that post-secondary students are capable of adapting their learning methods towards using mobile learning applications suited to their respective learning needs. This can be attributed towards how these students demonstrate a high level of willingness to incorporate mobile devices into their learning. Regardless of the content type, students are shown to demonstrate positive learning outcomes using mobile learning mobile apps. Studium illustrates that mobile learning apps are able to incorporate traditional learning theories and strategies that are proven to be effective including the spacing effect, spaced repetition, the lag effect and the Leitner system, while placing a focus on mental health using mindfulness breaks. This is significant because it is an element missing from many learning apps today. Areas that Studium needs to address is how the artificial intelligence will specifically determine which aspects of students' notes are relevant sections to form fill-in-blank fields. Studium will also need to address how professors would be involved in the distribution of the app so that intellectual property laws will not be violated since professors would ideally upload their lecture notes into the app for their students. Studium contributes towards establishing the trajectory of mobile learning applications that can foster positive learning outcomes in post-secondary education and change the way students traditionally learn in school using technological innovation. Since technology is constantly changing, so must the learning methods implemented in educational environments to allow for efficient learning outcomes and knowledge retention. 


\section{Bibliography}

Al Emran, M., \& Shaalan, K. (2014, September). A survey of intelligent language tutoring systems. In 2014 International Conference on Advances in Computing, Communications and Informatics (ICACCI) (pp. 393-399). IEEE.

Basoglu, E. B., \& Akdemir, O. (2010). A comparison of undergraduate students' English vocabulary learning: Using mobile phones and flash cards. Turkish Online Journal of Educational Technology-TOJET, 9(3), 1-7.

Butler, A. C. (2010). Repeated testing produces superior transfer of learning relative to repeated studying. Journal of Experimental Psychology: Learning, Memory, and Cognition, 36(5), 1118-1124.

D’Mello, S., \& Graesser, A. (2013). Design of dialog-based intelligent tutoring systems to simulate human-to-human tutoring. In Where Humans Meet Machines (pp. 233-269). Springer, New York, NY.

Fernández-lópez, Á., Rodríguez-Fórtiz, M. J., Rodríguez-Almendros, M. L., \& MartínezSegura, M. J. (2013). Mobile learning technology based on iOS devices to support students with special education needs. Computers \& Education, 61, 77-90.

GSMA Intelligence. (2018). Retrieved August 26, 2019, from https://www.gsmaintelligence.com/

Hasso Plattner Institute of Design at Stanford University. (2019). Design Thinking Process Diagram. [Portable Network Graphic]. Retrieved from http://dschool.stanford.edu./executive-education/dbootcamp.

Jerema, C. (2010, July 8). Your grades will drop. Maclean's. Retrieved from https://www.macleans.ca/education/uniandcollege/your-grades-will-drop/. 
Johnson, C. I., \& Mayer, R. E. (2009). A testing effect with multimedia learning. Journal of Educational Psychology, 101(3), 621.

Kang, S. H. (2016). Spaced repetition promotes efficient and effective learning: Policy implications for instruction. Policy Insights from the Behavioral and Brain Sciences, 3(1), 12-19.

Kapler, I. V., Weston, T., \& Wiseheart, M. (2015). Spacing in a simulated undergraduate classroom: Long-term benefits for factual and higher-level learning. Learning and Instruction, $36,38-45$.

McNamara, D. S., Crossley, S. A., \& Roscoe, R. (2013). Natural language processing in an intelligent writing strategy tutoring system. Behavior research methods, 45(2), 499-515.

Melton, A. W. (1970). The situation with respect to the spacing of repetitions and memory. Journal of Verbal Learning and Verbal Behavior, 9(5), 596-606.

Pennington, R., Paredes, J., Mai Yin, T. S. O. I., Timpte, C., Sauder, D., \& Pursell, D. (2010). Adapting to Student Learning Styles: Using Cell Phone Technology in Undergraduate Science Instruction. Journal of Systemics, 8(5), 1-5.

Rohrer, D., Dedrick, R. F., \& Stershic, S. (2014). Interleaved practice improves mathematics learning. Journal of Educational Psychology, 107(3), 900.

Searchpng (2018). Google Pixel 3 transparent mobile [Photograph]. Retrieved from https://www.searchpng.com/2018/12/01/google-pixel-3-transparent-mobile/.

Settles, B., \& Meeder, B. (2016, August). A trainable spaced repetition model for language learning. In Proceedings of the 54th Annual Meeting of the Association for Computational Linguistics (Volume 1: Long Papers) (pp. 1848-1858). 
Thornton, P., \& Houser, C. (2005). Using mobile phones in English education in Japan. Journal of computer assisted learning, 21(3), 217-228.

Trevors, G., Duffy, M., \& Azevedo, R. (2014). Note-taking within MetaTutor: interactions between an intelligent tutoring system and prior knowledge on note-taking and learning. Educational Technology Research and Development, 62(5), 507-528.

Zirguezi. (2012). Leitner system. [Scalable vector graphic]. Retrieved from https://commons.wikimedia.org/wiki/File:Leitner_system_alternative.svg. 